\title{
THERMAL MODELLING, SIMULATION AND EXPERIMENTAL VALIDATION OF HEAT ACCUMULATION IN A FRAMED GLASS CABIN
}

\author{
Tarun K. Bera, Sushank Dixit \\ Mechanical Engineering Department, Thapar University, Patiala, India \\ e-mail: tarunkumarbera@gmail.com
}

ANIRBAN BHATTACHARYA

Mechanical Engineering Department, Indian Institute of Technology (IIT) Patna, India

DEVEnder Kumar

Mechanical Engineering Department, Thapar University, Patiala, India

ARUn K. SAMANTARAY

Mechanical Engineering Department, Indian Institute of Technology (IIT) Kharagpur, India

\begin{abstract}
The present work concerns prediction of the amount of heat accumulation within the interior of a framed glass cabin and proposes some remedial measures to reduce temperature in the cabin. Various configurations such as double layer glass box filled with static air, static argon gas and flowing argon gas within the space between the two glass-layers are considered to conduct the experiments. Multi-physics bond graph models for these configurations are developed considering thermo-fluidic aspects. The experimental results are compared with the simulations using bond graph models. Though, direct application to a vehicle is not made, without loss of generality, the modelling and experimental procedure can be extended to analyze the heat accumulation inside a vehicle cabin when the vehicle is parked under direct sunlight.
\end{abstract}

Keywords: car cabin, experimental thermal analysis, bond graph modelling, double layer glass window

\section{Introduction}

During summer season, the environmental temperature generally varies between $40^{\circ} \mathrm{C}-50^{\circ} \mathrm{C}$ in southern Asia. The interior of a vehicle heats up significantly when parked in an open environment under direct sunlight in such conditions. As the heat wave passes through the glass, the wavelength of the electromagnetic wave increases, and higher wavelength electromagnetic waves cannot escape outside the car compartment. Thus, the heat entrapment expedites interior temperature of the car by nearly $20^{\circ} \mathrm{C}$ to $30^{\circ} \mathrm{C}$ above the surrounding atmosphere (Dadour et al., 2011).

As a solution to the problems, vanadium dioxide coating for window glasses has been proposed (Chen et al., 2012). This multilayer coating structure is transparent to visible light and is opaque to infrared light at high temperature. A mathematical study was done in (Xamána et al., 2014) on two layer windows with a solar control film. It was shown therein that the use of the solar control film along with the double pane window reduces the heat flow from inside to outside by up to $52 \%$. Transmittance of solar radiation through the glazed window can be reduced by using two glass panes without any air space between these panes (Mazzoni, 1977). The effect of solar radiation over the air flow and temperature distribution in the compartment of a car was studied (Lee et al., 2014). The thermal modelling of the car cabin and controlling the temperature by means of a fuzzy logic controller were developed in (Sanaye et al., 2012). 
A comprehensive review of different models developed to predict thermal comfort of vehicular cabins in addition to different experimental techniques was provided in (Alahmer et al., 2011). In (Al-Kayiem et al., 2010), experiments were performed by parking a salon car in direct sunlight and in an un-shaded area. Temperatures at 12 different locations were measured and then those values were used in 3-D CFD simulation performed with FLUENT software.

The bond graph is a multi-energy domain modelling tool (Merzouki et al., 2012). It was used therein to model the heat transfer from the external environment to the inside of a building. Many authors have worked on the bond graph modelling of thermo-fluidic systems: general modelling framework development, thermo-fluid library for process engineering systems (Samantaray et al., 2004), multi-phase systems (Brown, 2002) and applications to steam generators (Ould Bouamama et al., 2006).

The usual control of cabin temperature is based on the feed-back principle. However, when a vehicle moves from a shaded zone to a sunny area or vice-versa, the feed-back control is usually too slow to timely react due to the inherently slow dynamics of thermal systems. Therefore, it is preferable to use feed-forward control strategies with estimation of the cabin temperature change profile based on environmental temperature, air-conditioning load (number of passengers and interior furniture), and exposure to sunlight and its intensity. It is further useful to combine both feedback and feed-forward controls in a cascaded loop. However, such control laws require a well-developed and validated thermal model of the system. In the present work, bond graph models for such systems are developed and validated through experiments. The bond graph model of a double layer toughened glass with air (stagnant) and argon (stagnant and flowing) in between the two glasses is developed and experimentally validated.

\section{Thermal model of the system through the bond graph method}

A wooden frame structure with toughened glass windows each having a dimension of $548 \mathrm{~mm} \times 310 \mathrm{~mm} \times 5 \mathrm{~mm}$ is constructed (shown in Fig. 1a) and exposed to direct sunlight for experimentations. This assembly of wooden frame and the glass is assumed to be equivalent to the internal compartment of a car. The glass is properly sealed with sealant (clay based) so that no air can escape from the assembly. The frame is insulated with expanded polystyrene sheets at the top and the bottom panels so that no heat or little heat could escape from those sides.

(a)

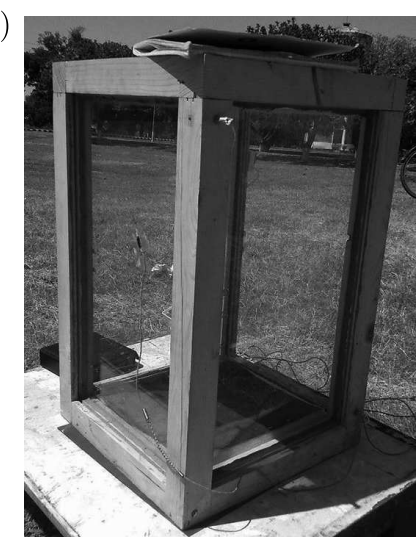

(b)

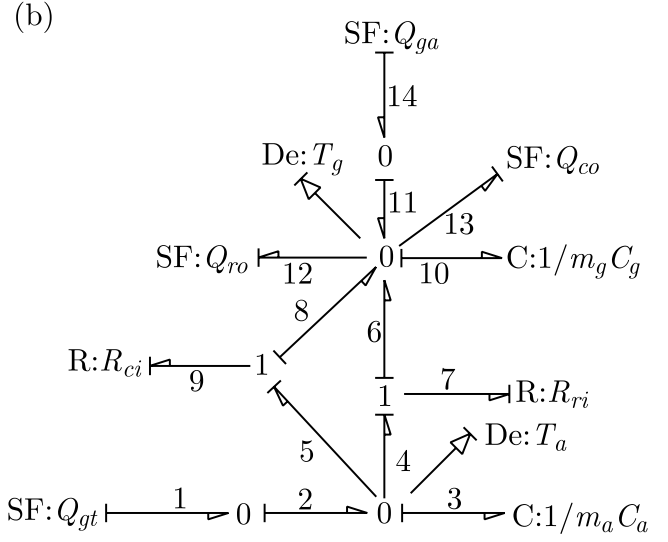

Fig. 1. (a) Cabin with single glass windows and (b) its bond graph model

\subsection{Thermal modelling of the cabin system with single layer glass panel windows}

The system made of single glass windows is modelled with the help of the bond graph so that the results can be validated experimentally. The bond graph model of the system is given in 
Fig. 1b. Note that the pseudo-bond graph formalism is adopted here for simplicity of formulation without unnecessarily bringing entropy into the picture.

The heat flux on the glass surface is absorbed, reflected or transmitted. An effort sensor or detector (De) measures the temperature $T_{g}$ of the glass. The stiffness $K 10$ of the $C 10$ element is given by

$$
K 10=\frac{1}{m_{g} C_{g}}
$$

where $m_{g}$ and $C_{g}$ are mass and specific heat of the glass panel, respectively.

As shown in Fig. 1b, SF14 represents the amount of heat absorbed by the glass surface $Q_{g a}$, and this is given by

$$
Q_{g a}=I_{r} A_{g} a_{g}
$$

where $I_{r}, A_{g}$ and $a_{g}$ are the irradiance, area and absorptivity of glass, respectively. The amount of heat radiated by the glass surface into the surroundings $Q_{r o}$ is modelled by SF12 element, and is given by

$$
Q_{r_{O}}=e_{g} \sigma A_{g}\left(T_{g}^{4}-T_{s}^{4}\right)
$$

where $e_{g}, \sigma, T_{g}$ and $T_{s}$ are the emissivity of glass, Stefan-Boltzmann constant, glass temperature and space temperature, respectively.

Some of the heat from the glass surface is taken away by the surrounding air through convection. $Q_{c o}$ is the heat flow by convection into the surroundings (modelled by SF13 in Fig. 1b), and is given by

$$
Q_{c o}=h_{a o} A_{g}\left(T_{g}-T_{a o}\right)
$$

where $h_{a o}$ and $T_{a o}$ are the convective heat transfer coefficient of the outside air and atmospheric temperature, respectively. $R_{c i}$ (modelled as R9 in the bond graph model) is the convective thermal resistance to the heat transfer between the inside air and the inner surface of the glass. The general heat transfer equation can be written as

$$
Q_{c i}=A h_{a i} \Delta T \quad Q_{c i}=\frac{\Delta T}{R_{c i}}
$$

Thus, the convective thermal resistance $R_{c i}$ is given by

$$
R_{c i}=\frac{1}{A h_{a i}}
$$

where $h_{a i}$ is the convective heat transfer coefficient of the fixed (inner) air.

Similarly, $R_{r i}$ is the radiative thermal resistance (denoted by the resistive element R7 in the bond graph model) to the radiative heat flow from the inside air to the surface of the glass. This heat flow can be obtained as

$$
T_{a c}-T_{g}=\frac{Q_{r i}}{A_{g} e_{a} \sigma\left(T_{a c}^{2}+T_{g}^{2}\right)\left(T_{a c}+T_{g}\right)}
$$

Defining the above in terms of resistance as $Q_{r i}=\Delta T / R_{r i}$, the radiative thermal resistance $R_{r i}$ can be obtained as

$$
R_{r i}=\frac{1}{A_{g} e_{a} \sigma\left(T_{a c}^{2}+T_{g}^{2}\right)\left(T_{a c}+T_{g}\right)}
$$


where $T_{a c}$ is the air temperature of the cabin. SF1 element represents the heat transmitted by the glass, and this heat is absorbed by the air of the cabin. Thus, the amount of heat transmitted $Q_{g t}$ by the glass is given by

$$
Q_{g t}=I_{r} A_{g} t_{g}
$$

where $t_{g}$ is the transmissivity of glass. The element C3 models the heat stored by the inside air and in the given integral causality, it outputs the effort information (temperature of the air of the cabin). Its stiffness is defined as

$$
K 3=\frac{1}{m_{a} C_{a}}
$$

where $m_{a}$ and $C_{a}$ are mass and specific heat of the inside air. The effort detector (De) is used to measure the temperature of the air inside the glass compartment. In the bond graph model given in Fig. 1b, all other parameters except $R_{r i}$ and the flow sources are constant values which depend upon material properties and geometric dimensions. The parameter values used in the simulation of the bond graph model shown in Fig. $1 \mathrm{~b}$ are given in Table 1 . The heat flux obtained from the experiment has been used as the input to the bond graph model of a single layer of the glass. The results obtained from the simulation of the bond graph model of the single glass layer configuration are shown in Fig. 2a. It is seen from Fig. 2a that the central cabin temperature increases very fast during the first half an hour and, after that, the rate of increase of temperature slows down. The maximum temperature reached after $2.5 \mathrm{~h}$ is about $59.4^{\circ} \mathrm{C}$ and, after that, the temperature becomes steady. The temperature of the glass also increases in the similar fashion as the cabin air; however, its value remains between temperatures of the cabin air and the atmospheric air. After almost $2 \mathrm{~h}$, the difference between temperatures of the central cabin and the atmosphere becomes almost steady at $20.3^{\circ} \mathrm{C}$. This simulation indicates that the temperature inside a closed car parked in direct sunlight increases rapidly.

Table 1. Parameter values of the single layer glass cabin

\begin{tabular}{|c|c|l|}
\hline Parameter & Value & \multicolumn{1}{c|}{ Description } \\
\hline \hline$a_{g}$ & 0.25 & Absorptivity of glass \\
\hline$A_{g}$ & $0.68 \mathrm{~m}^{2}$ & Total area of all four glasses \\
\hline$C_{a}$ & $919 \mathrm{~kJ} /(\mathrm{kg} \mathrm{K})$ & Specific heat of air \\
\hline$C_{g}$ & $720 \mathrm{~kJ} /(\mathrm{kg} \mathrm{K})$ & Specific heat of glass \\
\hline$e_{a}$ & 0.01 & Emissivity of air \\
\hline$e_{g}$ & 0.9 & Emissivity of glass \\
\hline$h_{a i}$ & $8 \mathrm{~W} / \mathrm{m}^{2} \mathrm{~K}$ & Convective heat transfer coefficient of fixed air \\
\hline$h_{a o}$ & $10 \mathrm{~W} / \mathrm{m}^{2} \mathrm{~K}$ & $\begin{array}{l}\text { Heat transfer coefficient of outside } \\
\text { air with speed of } 14 \mathrm{~km} / \mathrm{h}\end{array}$ \\
\hline$I_{r}$ & $110 \mathrm{~W} / \mathrm{m}^{2}$ & Heat flux \\
\hline$m_{a}$ & $0.063 \mathrm{~kg}$ & Mass of air inside cabin \\
\hline$m_{g}$ & $23.4 \mathrm{~kg}$ & Mass of glass \\
\hline$t_{g}$ & 0.5 & Transmissivity of glass \\
\hline$T_{s}$ & $12 \mathrm{~K}$ & Temperature of space \\
\hline$\sigma$ & $5.67 \cdot 10^{-8}$ & Boltzmann constant \\
\hline
\end{tabular}

\subsection{Thermal modelling of the cabin system with air-trapped two-layer glass panel windows}

In the second phase of the experiment and simulation, two layers of toughened glass having dimensions of $548 \mathrm{~mm} \times 310 \mathrm{~mm} \times 5 \mathrm{~mm}$ are used in each window panel. These two layers are 
(a)

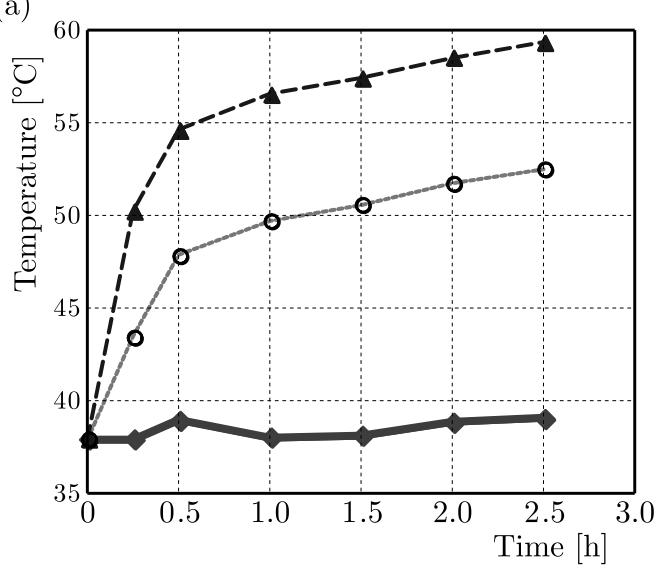

(b)

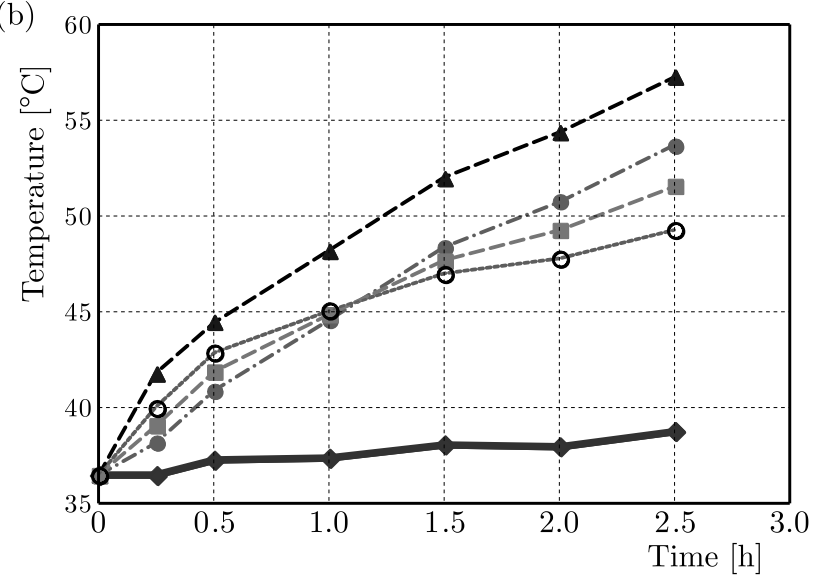

$$
\begin{array}{ll}
\text { - Surrounding temperature } & -\rightarrow-\text { Central cabin temperature (simulation) } \\
\text {-.-- Inner glass temperature (simulation) } & -- \text { - Trapped air temperature (simulation) }
\end{array}
$$

Fig. 2. Simulation results of (a) single layer glass and (b) double layer glass with entrapped air

assembled together in such a way that there is a fixed gap of $10 \mathrm{~mm}$ in between them. For this purpose, some separators are used. This entire setup is placed in an open environment under direct sunlight. The bond graph model of this modified system is shown in Fig. 3a. A part of the heat flux falling on the outer glass is absorbed by the glass; a part is reflected back and the remaining part is transmitted. The heat absorbed by the outer glass is represented by $Q_{g a 2}$ and is modelled by the SF14 element. As there are two layers of glasses separated by the air gap of $10 \mathrm{~mm}$, the trapped air absorbs some part of the heat transmitted by the outer glass. The remaining transmitted heat after getting absorbed by the air is reflected by the inner glass. From this reflected heat, again a part of the heat is absorbed by the air present in between the two glasses. The rest of the reflected heat after getting absorbed by the air in between the two glasses is further absorbed by the outer glass. So, the total heat absorbed $\left(Q_{g a 2}\right)$ by the outer glass is

$$
Q_{g a 2}=I_{r} A_{g} a_{g}+I_{r} A_{g} t_{g}\left(1-a_{a}\right) r_{g}\left(1-a_{a}\right) a_{g}
$$

where $a_{a}$ and $r_{g}$ are absorptivity of air and reflectivity of glass, respectively. The heat radiated and convected from the outer glass are expressed by (2.3) and (2.4), respectively. The radiative thermal resistance is obtained by replacing $T_{a c}$ and $T_{g}$ by $T_{a 2}$ (temperature of the atmospheric air present in between two glasses) and $T_{g a 2}$ (temperature at the outer glass) in (2.8). The total amount of heat $Q_{a a 2}$ absorbed by the air in between the two glasses is given by

$$
Q_{a a 2}=I_{r} A_{g} t_{g} a_{a}+I_{r} A_{g} t_{g}\left(1-a_{a}\right) r_{g} a_{a}
$$

The temperature of the inner glass is detected by the effort detector (De) connected to $0_{g 1}$-junction. The heat absorbed $Q_{g a 1}$ by the inner glass is given by

$$
Q_{g a 1}=I_{r} A_{g} t_{g}\left(1-a_{a}\right) a_{g}
$$

The transmitted heat $Q_{g t 1}$ that directly enters into the cabin is given by

$$
Q_{g t 1}=I_{r} A_{g} t_{g}\left(1-a_{a}\right) t_{g}
$$

The parameter values in the earlier simulations are given in Table 1, and the additional parameters related to the double layer configuration are given in Table 2. 

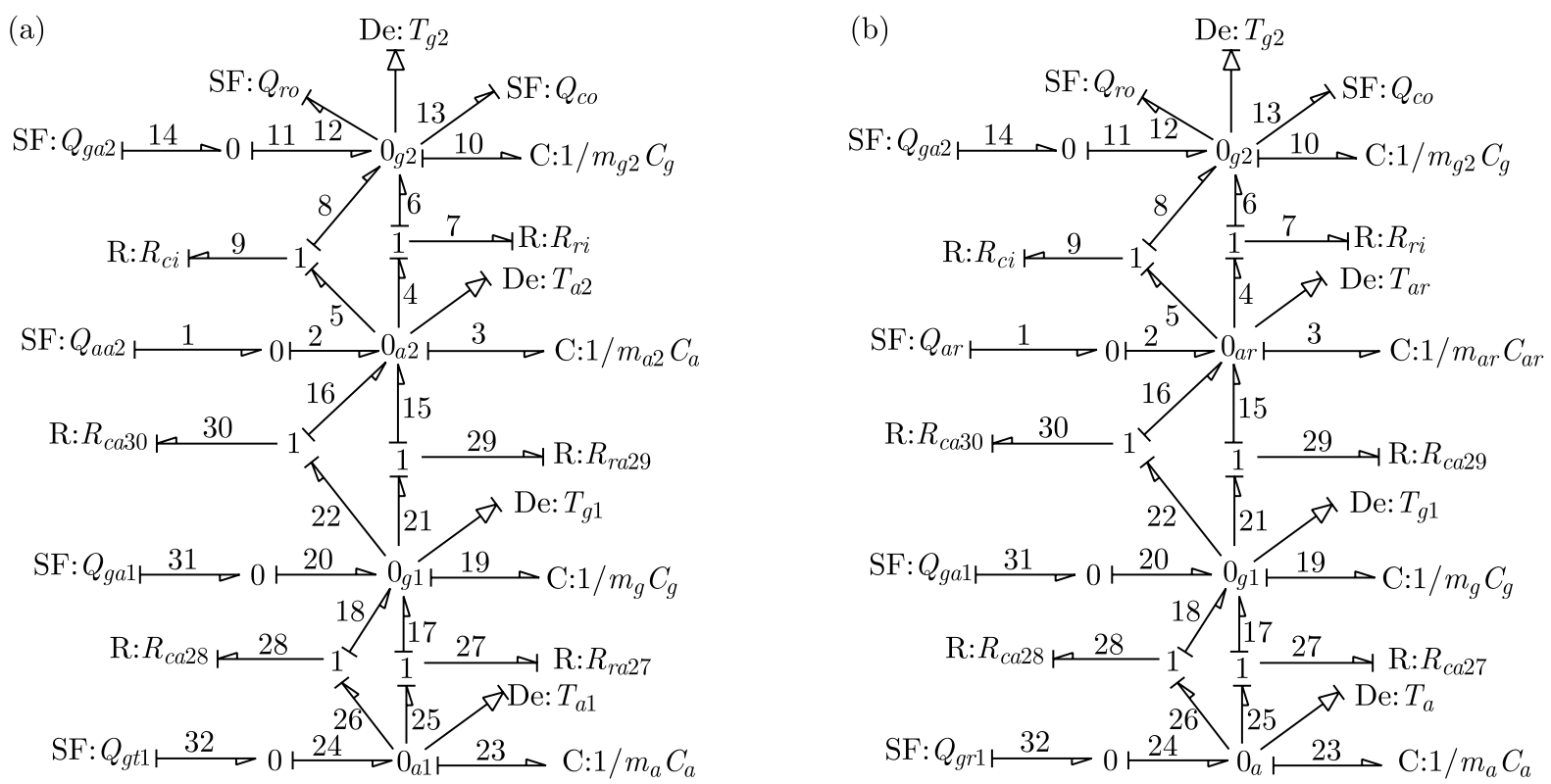

Fig. 3. Bond graph model of (a) double glass cabin with trapped air and (b) double layer glass cabin with entrapped argon

Table 2. Parameter values of the double layer glass cabin with entrapped air

\begin{tabular}{|c|c|l|c|c|l|}
\hline Parameter & Value & \multicolumn{1}{c|}{ Description } & Parameter & Value & Description \\
\hline \hline$a_{a}$ & 0.01 & Absorptivity of air & $m_{g 1}$ & $23.4 \mathrm{~kg}$ & Mass of outer glass \\
\hline$I_{r}$ & $118 \mathrm{~W} / \mathrm{m}^{2}$ & Heat flux & $m_{g 2}$ & $23.4 \mathrm{~kg}$ & Mass of inner glass \\
\hline$m_{a 2}$ & $0.00806 \mathrm{~kg}$ & $\begin{array}{l}\text { Mass of air present } \\
\text { between two glasses }\end{array}$ & $r_{g}$ & 0.25 & Reflectivity of glass \\
\hline
\end{tabular}

The results obtained from simulations performed are shown in Fig. 2b. The initial temperature of atmosphere is $36.5^{\circ} \mathrm{C}$. The temperature of the central cabin after $2.5 \mathrm{~h}$ becomes $57.3^{\circ} \mathrm{C}$, whereas for the single glass this temperature is $59.4^{\circ} \mathrm{C}$ although the heat flux in the double glass layer configuration $\left(118 \mathrm{~W} / \mathrm{m}^{2}\right)$ is greater than that in the single glass configuration $\left(110 \mathrm{~W} / \mathrm{m}^{2}\right)$. Note that the environmental conditions for both simulations are different as they have been conducted in different times. The maximum rise of the cabin temperature with the double glass layer configuration is found to be $18.6^{\circ} \mathrm{C}$. The inner glass temperature is less than the outer glass temperature for up to $1 \mathrm{~h}$ duration after exposure to direct sunlight. However, after the initial $1 \mathrm{~h}$ duration, the inner glass temperature exceeds the out glass temperature. Another important observation is that the cabin air temperatures increases faster than the entrapped air.

\subsection{Thermal modelling of the cabin system with argon-trapped two-layer glass panel windows}

The experiments for this configuration are performed in a similar manner to that performed for the double glass layers with argon entrapped in between the glasses. The bond graph model is given in Fig. 3b, which is similar to Fig. 3a in its structure. The total heat $Q_{g a 2}$ absorbed by the outer glass is given by

$$
Q_{g a 2}=I_{r} A_{g} a_{g}+I_{r} A_{g} t_{g}\left(1-a_{a r}\right) r_{g}\left(1-a_{a r}\right) a_{g}
$$

where $a_{a r}$ is the absorptivity of argon. The total heat $Q_{a r}$ absorbed by the argon gas is given by

$$
Q_{a r}=I_{r} A_{g} t_{g} a_{a r}+I_{r} A_{g} t_{g}\left(1-a_{a r}\right) r_{g} a_{a r}
$$


where $R_{c a 30}\left(1 /\left(A h_{a r}\right)\right.$ and the $R_{r a 29}$ are convective and the radiative thermal resistances, respectively, for argon present between the outer and inner glass. The heat absorbed by the inner glass is given as

$$
Q_{g a 1}=I_{r} A_{g} t_{g}\left(1-a_{a r}\right) a_{g}
$$

Out of the total heat transmitted by the outer glass, some of the heat is absorbed by the argon gas and the inner glass. The remaining heat is transmitted through the inner glass into the internal chamber of the closed cabin. This transmitted heat $Q_{g t 1}$ is given by

$$
Q_{g t 1}=I_{r} A_{g} t_{g}\left(1-a_{a r}\right) t_{g}
$$

Most of the parameter values used in the simulation of the bond graph model developed in Fig. $3 \mathrm{~b}$ are given Table 1 and Table 2 . The values of the modified and additional parameters are listed in Table 3.

Table 3. Parameter values for the double layer glass cabin with entrapped argon

\begin{tabular}{|c|c|l|c|c|l|}
\hline Parameter & Value & \multicolumn{1}{|c|}{ Description } & Parameter & Value & \multicolumn{1}{|c|}{ Description } \\
\hline \hline$a_{a r}$ & 0.1 & Absorptivity of argon & $h_{a r}$ & $5.3 \mathrm{~W} /\left(\mathrm{m}^{2} \mathrm{~K}\right)$ & $\begin{array}{l}\text { Heat transfer } \\
\text { coeff. of argon }\end{array}$ \\
\hline$C_{a r}$ & $520 \mathrm{~kJ} /(\mathrm{kg} \mathrm{K})$ & Specific heat of argon & $I_{r}$ & $100 \mathrm{~W} / \mathrm{m}^{2}$ & Heat flux \\
\hline$e_{a r}$ & 0.05 & Emissivity of argon & $m_{a r}$ & $0.01209 \mathrm{~kg}$ & Mass of argon \\
\hline
\end{tabular}

The simulation results for the double layer glass cabin with entrapped argon are shown in Fig. 4a. The initial temperature of the surrounding is $36^{\circ} \mathrm{C}$. The temperature of the central cabin after $2.5 \mathrm{~h}$ is $57.08^{\circ} \mathrm{C}$, whereas for the double glass with air, this temperature is $7.3^{\circ} \mathrm{C}$. The temperature differences between the central cabin and the atmosphere are $16.7^{\circ} \mathrm{C}$ and $18.6^{\circ} \mathrm{C}$, respectively, for the double layer glass with argon and air insulation between the glass layers. So, as expected, the use of the argon gas between the glass layers yields better thermal insulation.
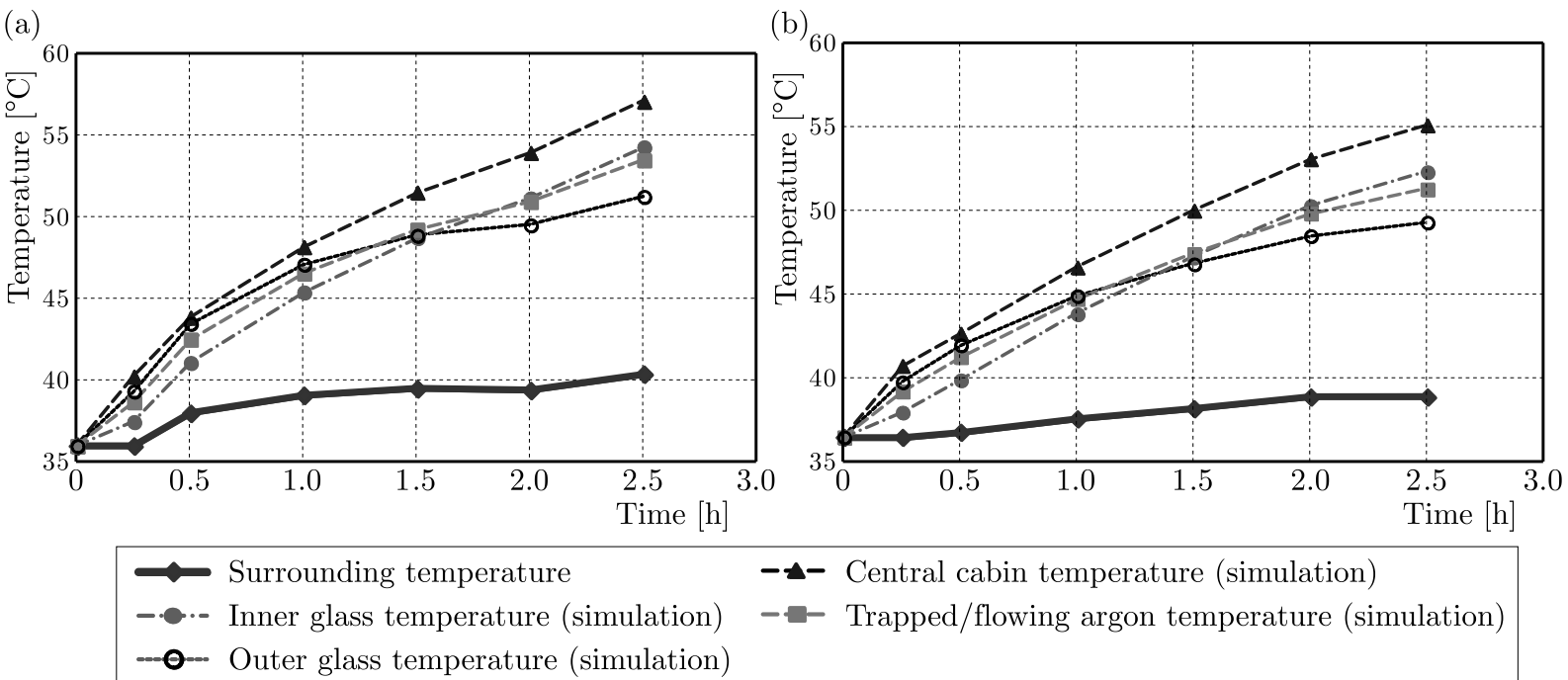

- $\mathbf{A}$ - Central cabin temperature (simulation)

- - Trapped/flowing argon temperature (simulation)

Fig. 4. Simulation results of the double layer glass with (a) entrapped and (b) flowing argon

\subsection{Thermal modelling of the cabin system with flowing argon between two-layer glass panel windows}

This configuration is intended for the double layer glass with the argon gas continuously flowing through the system with a flow rate of $0.403182 \mathrm{~g} / \mathrm{s}$. The bond graph model of the 
system is similar to that for the earlier case. However, the heat transfer coefficient for flowing argon is different. The parameter values for the simulation are given Tables 1, 2 and 3. The convective heat transfer coefficient $h_{a r}$ of argon is considered as $7 \mathrm{~W} /\left(\mathrm{m}^{2} \mathrm{~K}\right)$ for the flow rate of $0.403182 \mathrm{~g} / \mathrm{s}$. The simulation results for the double layer glass with flowing argon are shown in Fig. 4b. The initial temperature of the surrounding is $36.5^{\circ} \mathrm{C}$. The temperature of the central cabin after $2.5 \mathrm{~h}$ is $55.07^{\circ} \mathrm{C}$ whereas for the double glass with static argon, this temperature is $57.08^{\circ} \mathrm{C}$. The steady-state temperature difference between the central cabin and the atmosphere is $16.7^{\circ} \mathrm{C}$ and $16.1^{\circ} \mathrm{C}$ for the double glass layer configuration with static argon and with flowing argon, respectively. So, flowing argon between the two glass layers is preferable.

\section{Experimental validation}

\subsection{Selection of the material and sensors}

The materials and sensors used for the development of the experimental setup are wooden frame, toughened glass, separator, air-oxygen separator, thermocouple, digital thermometer, argon cylinder, pipe and T-connectors as shown in Fig. 5. The dimension of the frame has been selected according to size of the toughened glass. The dimensions of the wooden frame are $411.6 \mathrm{~mm} \times 411.6 \mathrm{~mm} \times 649.6 \mathrm{~mm}$. Laminated glass and toughened glass are widely used in vehicles due to its non-breaking tendency. The size of the toughened glass used is $310 \mathrm{~mm} \times 548 \mathrm{~mm} \times 5 \mathrm{~mm}$. A solar power meter is used to measure the solar heat intensity $x$, and this value is used to calculate the solar heat flux $Y$ as obtained after calibrating with a pyranometer $\left(R^{2}=0.99\right)$

$$
Y=0.745 x+1.839
$$

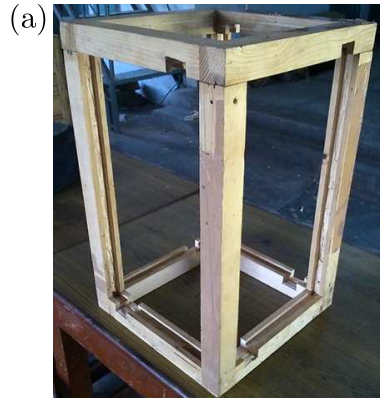

(d)

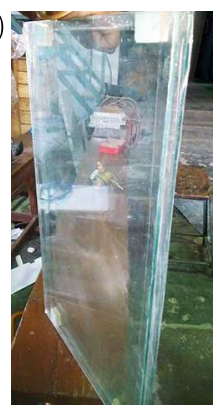

(b)

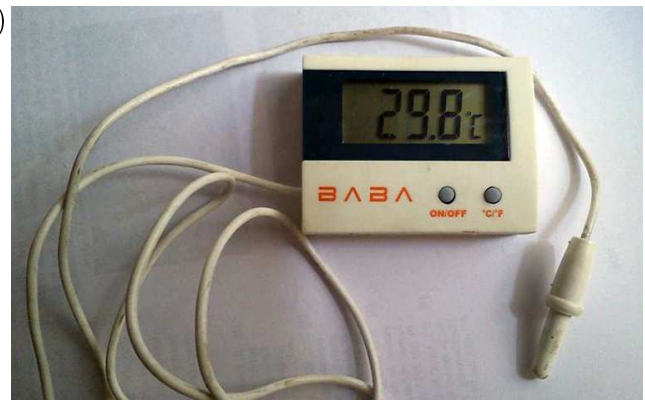

(e)

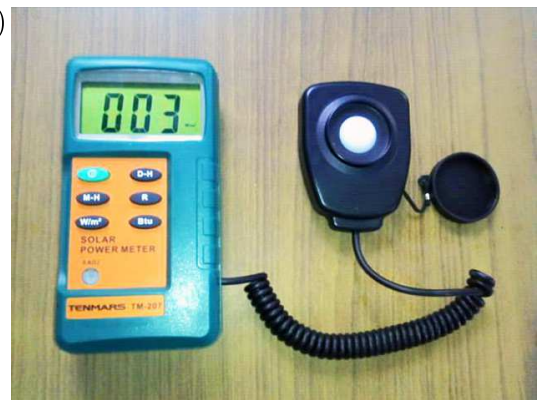

(c)

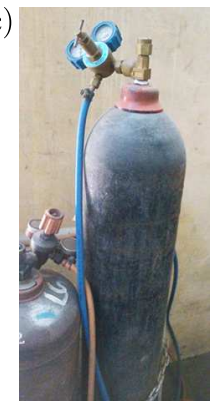

(f)

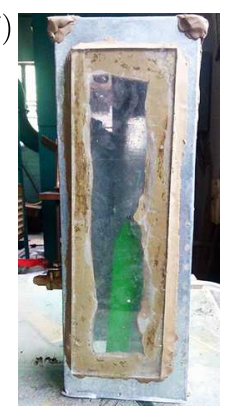

Fig. 5. Experimental accessories (a) glass supporting structure, (b) digital thermometer, (c) argon cylinder, (d) separator, (e) solar power meter and (f) argon-oxygen separator 


\subsection{Experimentation on the cabin system with single layer glass panel windows}

It is the first phase of the experiment; toughened glass having dimensions $548 \mathrm{~mm} \times$ $310 \mathrm{~mm} \times 5 \mathrm{~mm}$ is fitted into the wooden frame. The glass is properly sealed with the sealant (clay) so that no air can escape from the assembly. The frame is insulated with expanded polystyrene from the top and the bottom so that very little heat could escape. The entire setup is exposed to direct solar heat waves. The heat starts to accumulate in the interior of the cabin by means of conduction, convection and radiation. Most of the accumulated heat is due to the radiation. Two digital thermometers are used to measure cabin temperature and atmospheric temperature. A solar power meter is used to measure the solar light intensity which eventually gives the value of the solar heat flux. The experiment starts at 11 am on a hot sunny day of summer and readings are taken at an interval of 15 minutes for the first half hour and then onwards at 30 minute intervals. Initially, the temperature difference between the atmosphere and the cabin compartment is less, but as the time passes, this temperature difference goes on increasing. The results obtained by the experiment are compared with the results from the bond graph modelling, and these are shown in Fig. 6a. As shown in Fig. 6a, the simulated results for the central cabin temperature are very close to those obtained from the experiment.
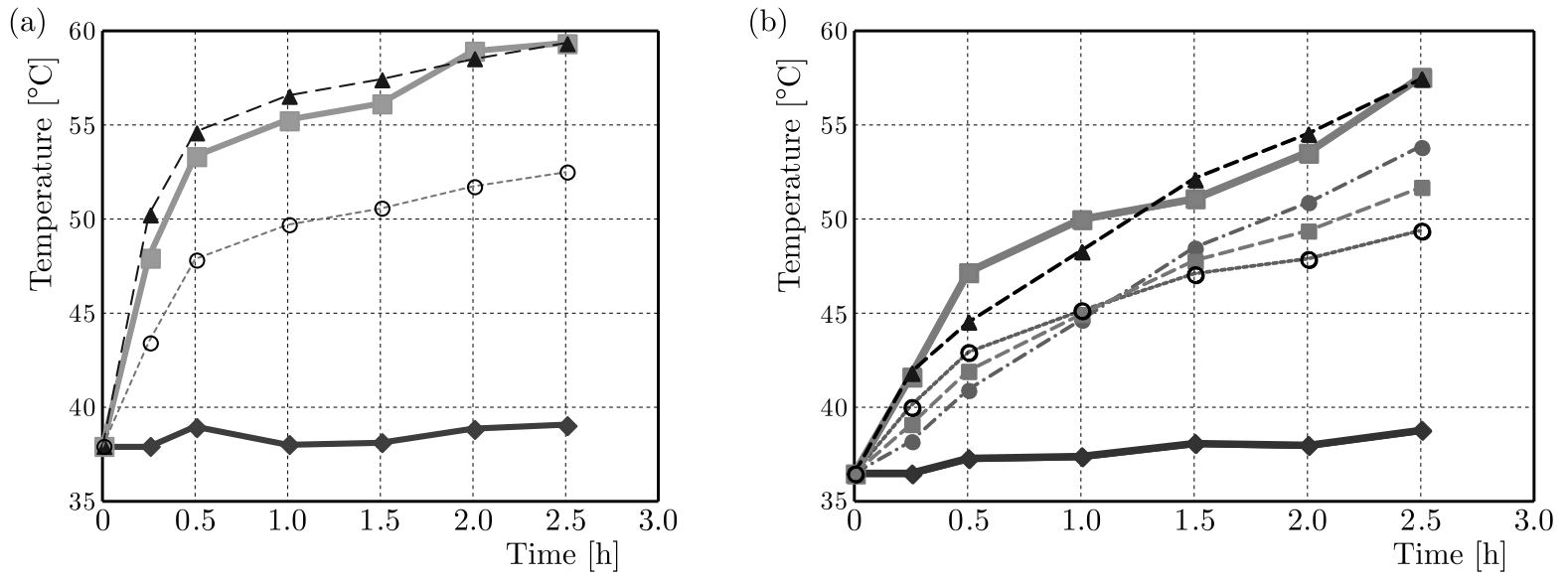

\begin{tabular}{|c|c|}
\hline Surrounding temperature & - Central cabin temperature (experimental) \\
\hline - $\mathbf{A}$-・ Central cabin temperature (simulation) & -•-- Inner glass temperature (simulation) \\
\hline- - & --o-- Outer glass temperature (simulation) \\
\hline
\end{tabular}

Fig. 6. Experimental vs simulation results for (a) single layer glass and (b) double layer glass with entrapped air

\subsection{Experiments on the cabin system with air-trapped double layer glass panel windows}

The top and the bottom portion of the cabin prepared with the double layer glass panel are covered by expanded polystyrene sheets so that little heat could get escape through them. Two digital thermometers are used to measure the temperature inside and outside the cabin. The basic principle of such a type of arrangement is to form a barrier for the heat flow. The toughened glass and trapped air inside the two layers of glasses have low thermal conductivity and thus inhibit heat transfer. The experimental and simulation results for this configuration are shown in Fig. $6 \mathrm{~b}$ where the atmospheric temperature (an input to the simulation model) has a variation of about $2^{\circ}-3^{\circ} \mathrm{C}$. Although there is not much variation in the atmospheric temperature, the central cabin temperature goes on increasing. Initially, the temperature difference between the central cabin temperature and the atmospheric temperature is less, but with time, this temperature difference increases. When compared to Fig. 6a, i.e. the experiment performed on the single 
layer glass, the temperature difference obtained in the double layer glass panel configuration is quite less.

\subsection{Experiments on the cabin system with argon-trapped double layer glass panel windows}

The experiments are performed on the double glass with argon entrapped in between the glasses. A hole of $3 \mathrm{~mm}$ is drilled through the separator. A pipe of $3 \mathrm{~mm}$ diameter is inserted through the hole of the separator and this pipe is further connected to the argon gas cylinder. This assembly is prepared so as to fill the gap with argon (stored in the cylinder) and prevent any leakage. A constant flow of the argon gas is maintained in all four double layer glass assemblies so that atmospheric air is displaced by the pressurized argon gas. The constant flow is checked by counting the bubbles coming out from the outlet pipe which is dipped in water. When the bubble count per time unit is stabilized, the argon gas flow is stopped. The displacement of the atmospheric air by the pressurized argon gas is also verified by a parallel arrangement installed during the experiment. In this arrangement, the outlet line is made to pass through a closed chamber (Fig. 5f) having a burning candle inside it. The candle stops burning as soon as there is no oxygen available in the outlet pipe coming out from the double layered glass assemblies. When the pressure at the supply and at the outlet of the assembly of the glasses becomes equal, it indicates that the argon gas has been completely filled in the gap of the two glasses. Then the entire setup is exposed to the sunlight at the scheduled time.

The experimental and simulation results for this case are shown in Fig. 7a. During this experiment, the atmospheric temperature ranges between $36^{\circ}-40.4^{\circ} \mathrm{C}$ and the rise in temperature of the central cabin is $16.7^{\circ} \mathrm{C}$. Compared to the results obtained for the single glass panel cabin $\left(20.3^{\circ} \mathrm{C}\right)$ and the double layer glass panel cabin with air insulation $\left(18.6^{\circ} \mathrm{C}\right)$, the rise in the cabin temperature is less for the double layer glass panel cabin with argon gas insulation between the glass layers. The cabin temperature has fallen by nearly $3.6^{\circ} \mathrm{C}$ from the single layer glass panel configuration.
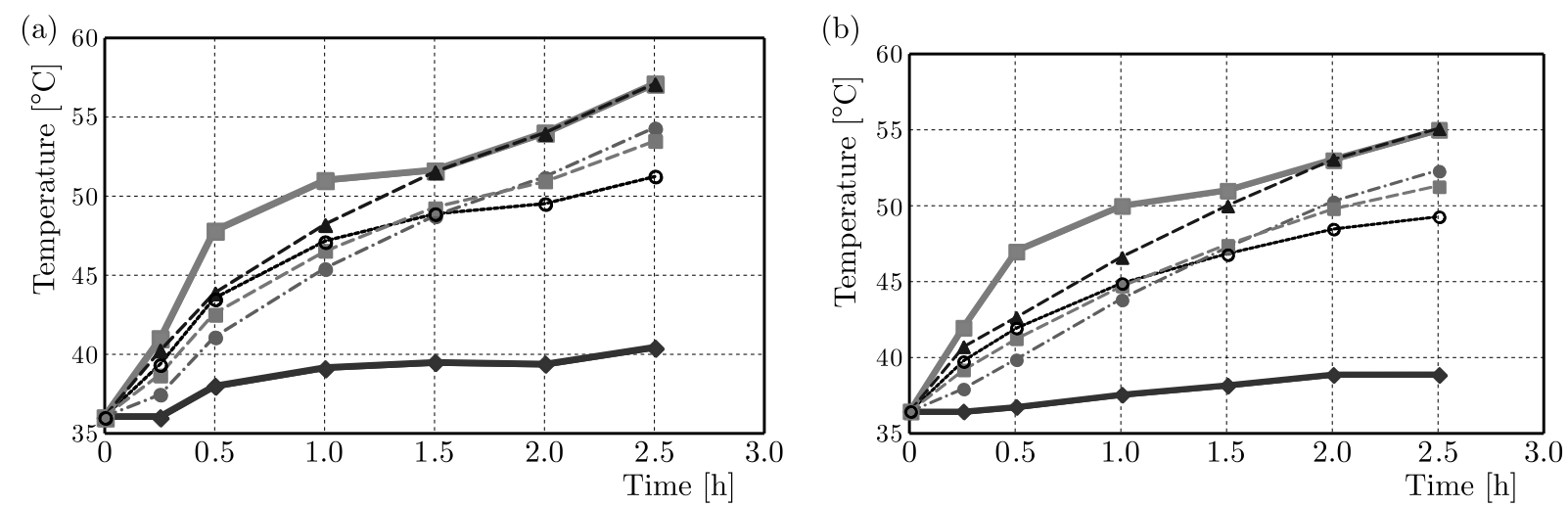

\begin{tabular}{|c|c|}
\hline$\sim$ Surrounding temperature & - Central cabin temperature (experimental) \\
\hline$\rightarrow-$ Central cabin temperature (simulation) & -.-- Inner glass temperature (simulation) \\
\hline - - - Trapped/flowing argon temperature (simulation) & ---- Outer glass temperature (simulation) \\
\hline
\end{tabular}

Fig. 7. Experimental vs simulation results for the double layer glass with (a) entrapped argon and (b) flowing argon

\subsection{Experiments on the cabin system with two-layer glass panel windows and argon flowing between the glass layers}

Experiments were further conducted using the same setup with argon flowing at a rate of $0.403 \mathrm{~g} / \mathrm{s}$ through the gap between the two glass layers. The simulation and experimental results 
for this configuration are shown in Fig. $7 \mathrm{~b}$. The temperature difference $\left(16.1^{\circ} \mathrm{C}\right)$ between the central cabin temperature and atmospheric temperature is lower than that for the single glass layer $\left(20.3^{\circ} \mathrm{C}\right)$ and the double glass with the entrapped air $\left(18.6^{\circ} \mathrm{C}\right)$, but nearly the same as that of the double glass with entrapped argon $\left(16.7^{\circ} \mathrm{C}\right)$. The continuous flow of argon helps carrying away the heat outside the cabin and, therefore, reduces a rise in the cabin temperature. This reduction could be more effective if the argon flow rate is increased. In addition, while the sealed glass panels with permanently entrapped air or argon can be easily fabricated as a unit, the flowing argon configuration requires additional components like air/argon pump, pipes, etc. due to which the manufacturing and maintenance problems encountered far outweigh the minor performance gain.

\section{Conclusions}

Experiments have been conducted in a closed cabin of toughened glass to understand the heat accumulation in the interior of a vehicle when it is exposed to direct sunlight. A bond graph model of the setup has been developed to perform simulation studies. The simulations and the experiments give an idea about the rate at which heat gets accumulated in the cabin. Replacing the single layer toughened glass panels with double layer toughened glass panels with static air trapped between the two glass layers, a reduction in the rate of increase of the cabin temperature has been observed. When the argon gas was trapped between the two glass layers, further reduction in temperature of the cabin air was observed. Moreover, when the argon gas was allowed to flow continuously at a slow flow rate, the rate of heat accumulation inside the cabin reduced further. The bond graph models developed for all these different configurations give very good predictions of the rate of heat accumulation or temperature of the cabin air. Such models can be used to develop predictive feed-forward or cascaded feedback and feed-forward control systems for cabin temperature regulation in the place of purely feedback controllers used in contemporary vehicles. This research work will be pursued further to deal with the heat transfer and storage through/in the roof and interior materials of a vehicle with aim to develop an optimized model-based control system of the cabin temperature.

\section{References}

1. Alahmer A., Mayyas O.A., Shan D., 2011, Vehicular thermal comfort models; a comprehensive review, Applied Thermal Engineering, 31, 995-1002

2. Al-Kayiem H.H., Firdaus Bin M., Sidik M. Munusammy Y.R.A.L., 2010, Study on the thermal accumulation and distribution inside a parked car cabin, American Journal of Applied Sciences, 7, 6, 784-789

3. Brown F.T., 2002, Non-iterative evaluation of multiphase thermal compliances in bond graphs, Journal of Systems and Control Engineering, 216, 1, 13-19

4. Chen X., Lv Q., Yi X., 2012, Smart window coating based on nanostructured $\mathrm{VO}_{2}$ thin film, International Journal for Light and Electron Optics, 123, 13, 1187-1189

5. Dadour I.R., Almanjahie I., Fowkes N.D., Keady G., Vijayan K., 2011, Temperature variations in a parked vehicle, Forensic Science International, 207, 205-211

6. Lee J.W., Jang E.Y., Lee S.H., Ryou H.S., Choi S., Kim Y., 2014, Influence of the spectral solar radiation on the air flow and temperature distributions in a passenger compartment, International Journal of Thermal Sciences, 75, 36-44

7. MAzZoni, 1977, Reducing solar radiation transmittance of installed glazing, US Patent, Application No. $710031,4,041663$ 
8. Merzouki R., Samantaray A.K., Pathak P.M., Ould Bouamama B., 2012, Intelligent Mechatronic Systems, London, Springer

9. Ould Bouamama B., Medjaher K., Samantaray A.K., Staroswiecki M., 2006, Supervision of an industrial steam generator. Part I: Bond graph modeling, Control Engineering Practice, 14, $1,71-83$

10. Samantaray A.K., Medjaher K., Ould Bouamama B., Staroswiecki M., DauphinTANGUY G., 2004, Component-based modelling of thermofluid systems for sensor placement and fault detection, Simulation, 80, 7/8, 381-398

11. Sanaye S., Dehghandokht M., FartaJ A., 2012, Temperature control of a cabin in an automobile using thermal modelling and fuzzy controller, Applied Energy, 97, 860-868

12. Xamána J., Pérez-Nuchmendia C., Arce J., Hinojosa J.F., del Socorro Álvarez-Garca G., Zavala-Guillén I., 2014, Thermal analysis for a double pane window with a solar control film for using in cold and warm climate, Energy and Buildings, 76, 429-439

Manuscript received April 5, 2016; accepted for print March 31, 2017 